\title{
Optimal Integrated Operation Strategy for Highway Toll System with Android Technology
}

\author{
Amruta Gadekar \\ Professor \\ Department of Computer Engineering \\ D.Y. Patil Institute of Engineering and Technology, \\ Ambi, Pune
}

\author{
Tanaji M. Andhale \\ Department of Computer Engineering \\ D.Y. Patil Institute of Engineering and Technology, \\ Ambi, Pune
}

\begin{abstract}
The use of Automated Tollbooth Collection (ATC) system uses the RFID Technology. by using this ATC system in many big cities would be an efficient and effective way towards the over crowding of the city highways in heavy congestions of traffic. As we know, transport is the power of our country's economy syatem. The payment system consist an application that automatically deduct the Toll Tax from the E-Wallet app which help in to fast processing of Toll collection and motivating cashless transactions. In this system we are focused on Automatic payment and Theft Vehicle detection. The existing Toll system have some problems as money corruption, vehicle congestion,time consumption and the stolen vehicle detection. The mentioned problems are the biggest issues at toll booths.Automated Toll Collection(ATC)system is used in toll collection without making heavy traffic and without wasting a time of peoples by using RFID technology. by using this ATC system, it will save time, i.e. by removing long waiting line as no need to stop the vehicle and no need of manual Tax Payment. In case of manual toll collection time wastage is much far worse as well as fuel wastage, and most important is the traffic conjuction the amount of air pollution that is produce at the toll booth system site is at very high level, so our developed system will reduce time wastage and not only reduce air pollution but also save fuel. The main purpose of this system is to reduce the traffic caused by manually toll tax payment in manual toll collection system and pass the authorized vehicle through toll barrier in a matter of few seconds without halt
\end{abstract}

\section{Keywords}

E-wallet; Tollbooths; Toll charge;ATC(Automated Toll Collection)

\section{INTRODUCTION}

Automated toll collection (ATC) is a technology enabling the automated collection of toll payments. It has been introduces by researchers and applied in various toll booths, highways, bridges, and tunnels requiring such a process. Automated Toll Collection system is expert in determining if the vehicle is registered or not in ATC databases, and then informing the authorities of toll tax payment violations, debits, and participating accounts. The RFID system having advantage of this technology is the capability to remove traffic jam in

\author{
Jayesh K. Salunke \\ Department of Computer Engineering \\ D.Y. Patil Institute of Engineering and Technology, \\ Ambi, Pune
}

tollbooths, specially in the festive seasons and holidays when traffic are more heavier than normal days. It is also a method by which to large complaints from motorists regarding the inconveniences involved in manually making toll tax payments at the tollbooths. Other than this obvious advantage, applying Automatted Toll Collection system could also benefit the toll booth operators.

An Automated Toll Collection system simply uses the radio frequency identification (RFID) technology. RFID technology is a generic term used to be identify technologies uses radio frequency waves to automatically identify the vehicular RFID Tag or objects. In 1948 RFID technology is firstly introduced when Harry Stockman wrote a paper exploring RFID technology as "Communication by Means of Reflected Power". RFID technology has used since then, and has been implemented in various applications. In general, RFID technology is used for tracing, tracking and identifying RFID Tag. A RFID system consists of a antenna, tag(transponder), reader/writer and computer server. The RFID transponder as better known as the RFID tag is a micro chip combined with an antenna system in a compact package. The micro chip uses logic circuits and memory to receive the data and send the data back to the RFID reader. These tags are classified into 2 types as active or passive tags. Active tags uses the internal battery that allow a large reading range, while passive tags are activated by the Radio frequency signal from its reader and these have short reading range.

The process flow of system is like first user has to be register on the etoll wallet app this app also cotain vehicle registration and payment process, the server will register all the details related to the vehicle and generates the user id and password to that particular user by this the owner is able to access their account, then registered vehicle passes the toll first the RFID Reader detects the RFID Tag this is taken as the input. the vehicle RFID Tag ID is then matches with the maintained database of the stolen vehicle.to detect the Vehicular ID match it with the stolen vehicle data. If in case the match is found means that the vehicle is stolen then the message will get send to the vehicle owner and the police admin then vehicle block from the Toll management and if not stolen then the toll tax will get deducted from the owners account by Ewallet system and the transaction will successful.the vehicle passes the tollbooth without any interference.if the balance is 

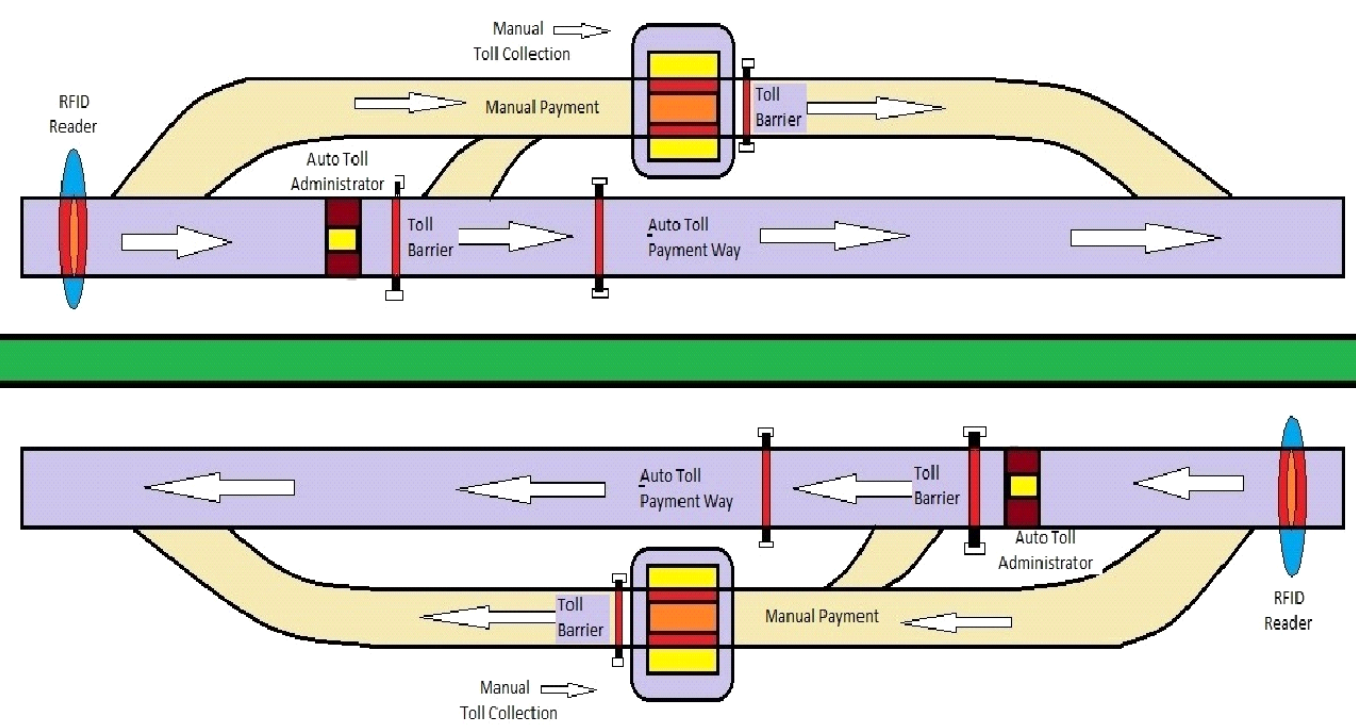

Fig Toll System View

The Following System Architecture shows Communicatio between the E-Wallet i.e Smart phone, Administratative server, databases, Arduino MicroController, vehicle and RFID Reader

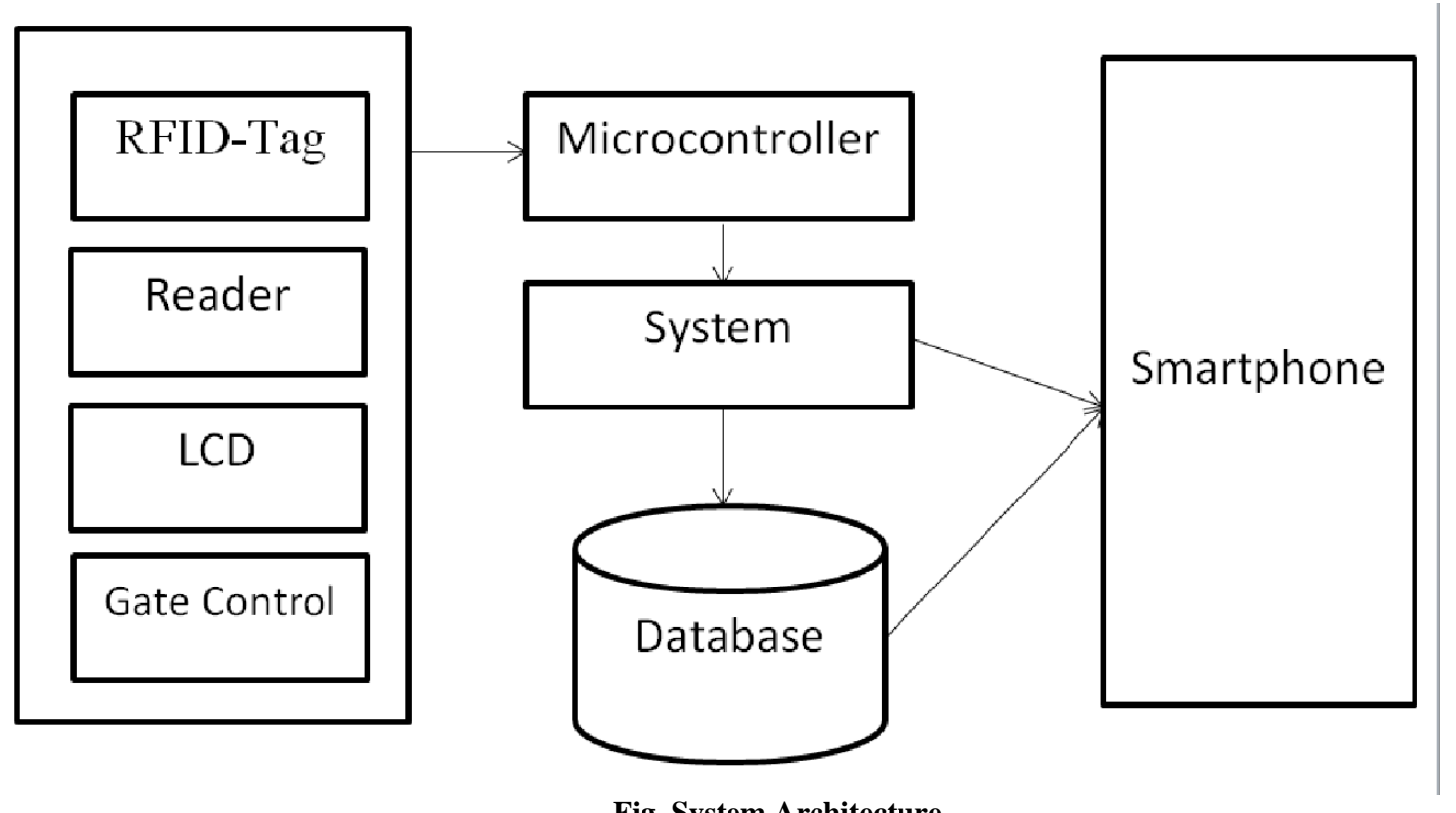

Fig. System Architecture

The Following System flow shows how the vehicle is pass through the ATC system and their Operations and how the Toll Module communicate with other. 


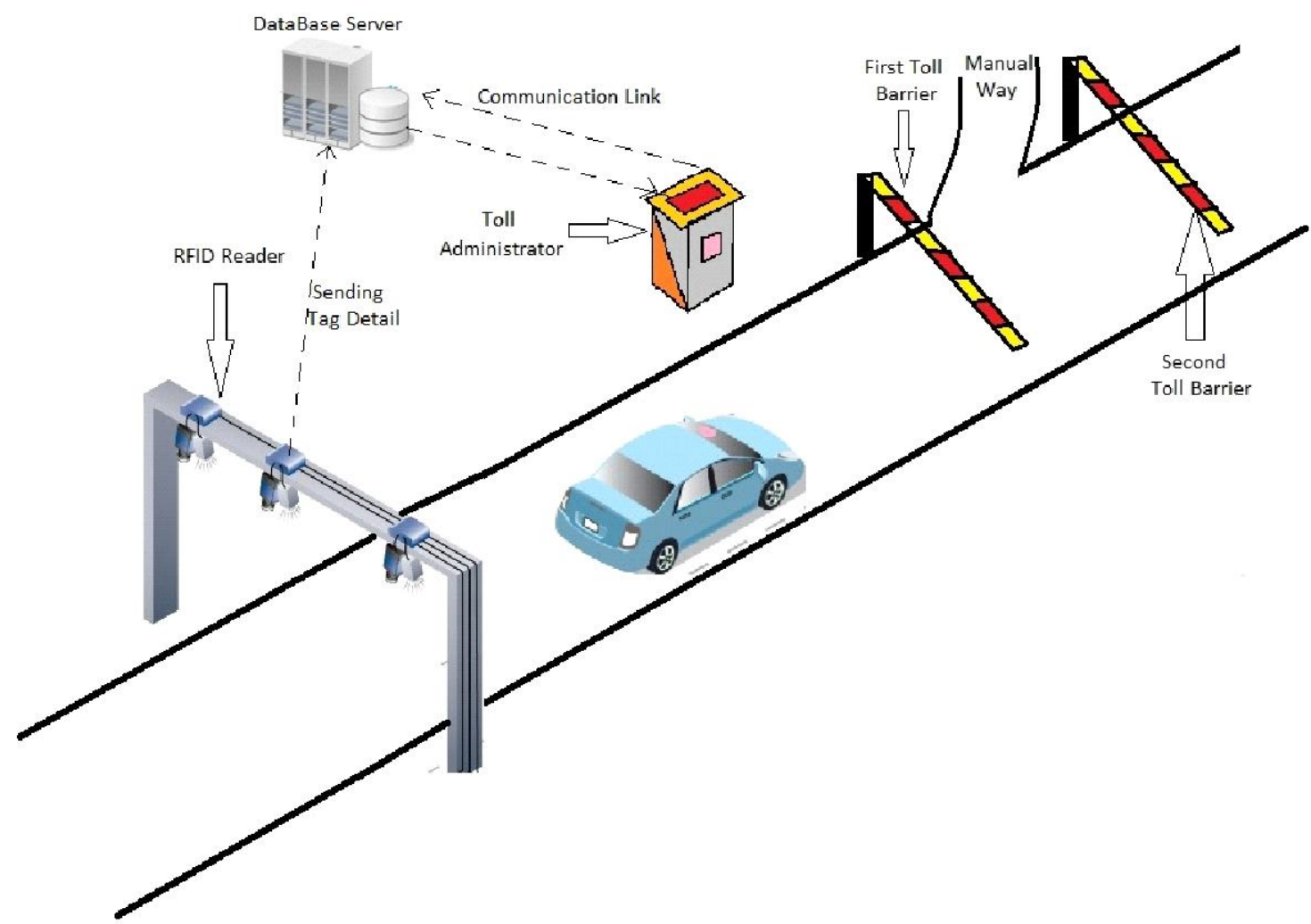

Fig. Vehicle Pass Process

There is 3 Cases of Vehicle Passing through the Toll System:

1. If any Theft Record is Found In the Database Server the First Toll Barrier is not get open.

2. if any theft record is not registered on that perticular vehicle then 1st barrier get open but Balance is insufficient then 2 nd barrier is not get open vehicle must have to go through the manual toll way

3. if the vehicle is not having Theft Record and also balance is sufficient for to payment then both Toll Barrier get open Vehicle Passes Toll without Stopping.

\section{LITERATURE SURVEY}

In [1], ANPRs (Automatic Number Plate Recognition) system has been employed which uses a cameras to captures the number plates of the vehicles and deducts the toll tax at by comparing it with the owners database.

In [2], the system is introduced on infrared sensors. In this system the user has to get the Infrared transmitter from the main toll booth. The transmitter will be charged by the toll booth and the users dataset will be stored in the microcontroller. When the vehicle enters at the toll booth the user will have to place the transmitter on the vehicle and turn it on. It nesessary in the line of sight of the receiver end. The receiver will validate the data from the transmitter with the database and the amount of toll tax will get deducted from account. It uses the stepper motor for control the gate.

In [3] also the main system uses the RFID technology. The microcontroller introduce in this system is PIC $18 \mathrm{~F} 4550$ and has been connected with the toll system. The RFID receiver senses the RFID tag coming in its range by radio waves and the toll tax is gets deducted from the account of the vehicle owner after all the related user detail is checked from the database. The IR senses the vehicle speed and motion for control the opening and closing of the toll gate. the stepper motor is used to access the gate. The all of the references given below have also use the RFID technique and the working of this is similar to [3] except the database creation and payment process methods. The authors have take the GSM module in their future scopes which we have use in our project.we also use the android app for user friendly enviroment.

\section{UML Diagram \\ 3.1 Sequence Diagram \\ 3.1.1 User Registration}




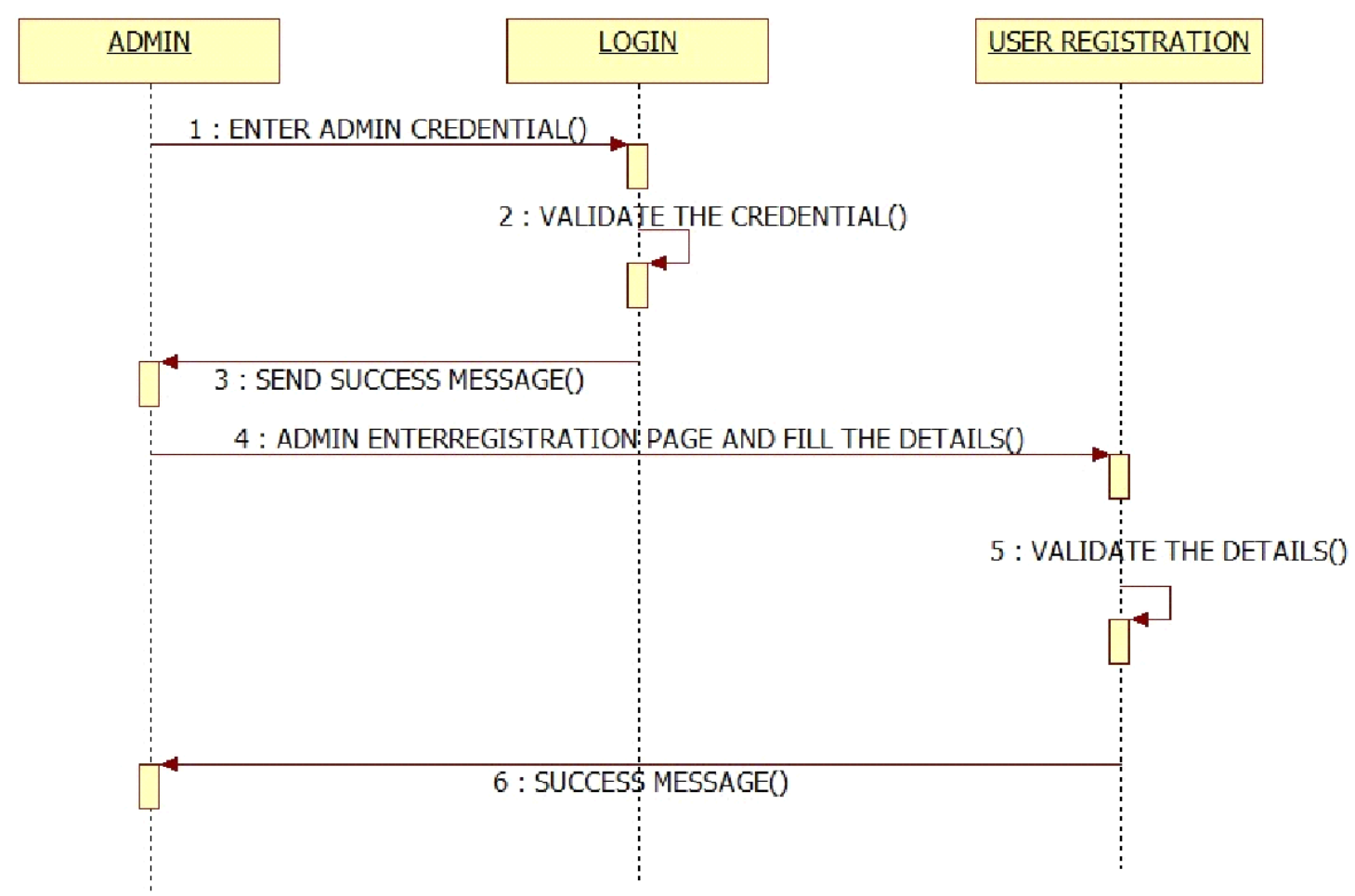

Fig. Sequence Diagram of User Registration

\subsection{Vehicle Complaint Registration}

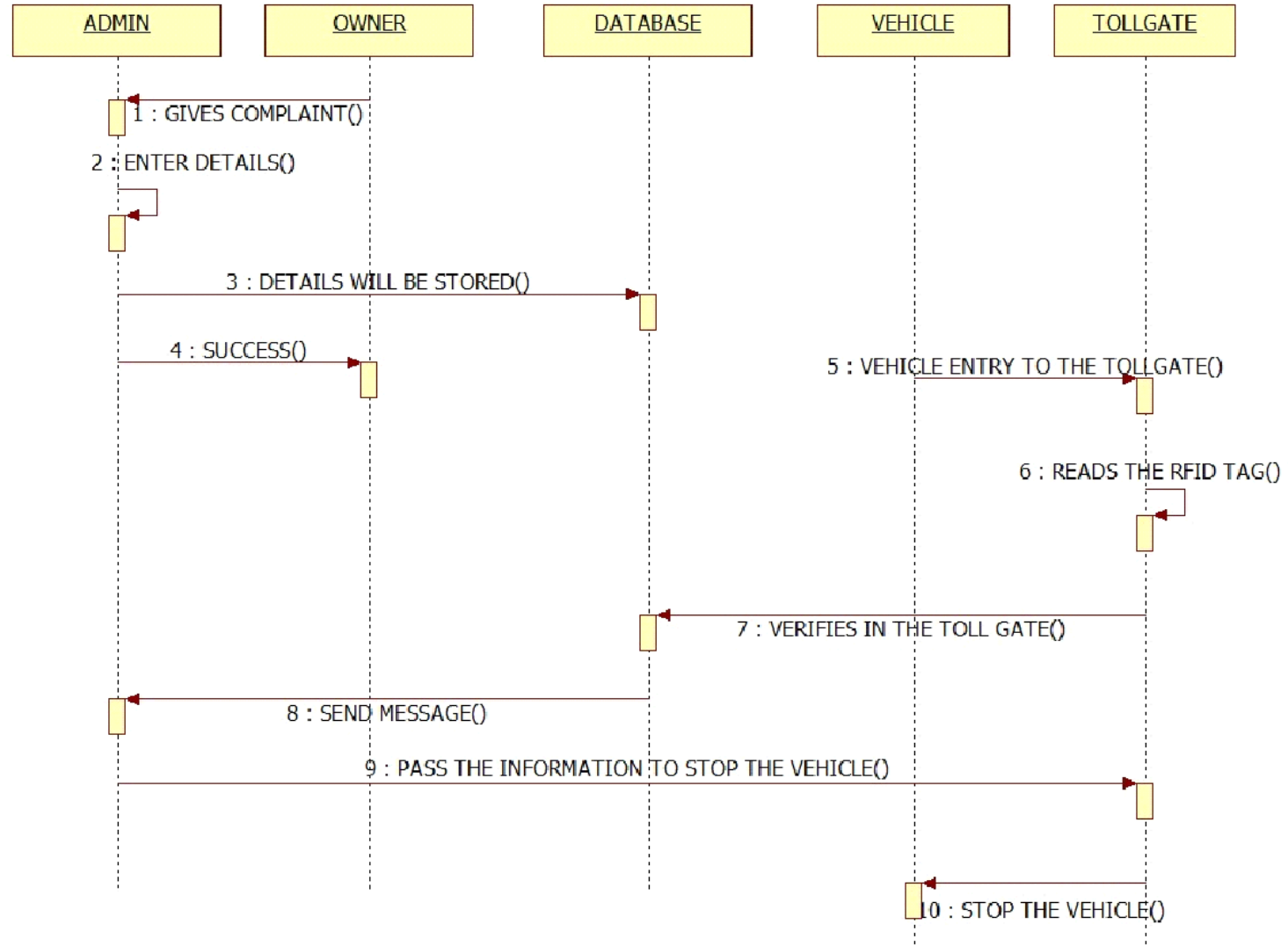

Fig. Sequence Diagram of Vehicle Complaint Registration 


\subsection{Process of Vehicle passing a tollbooth}

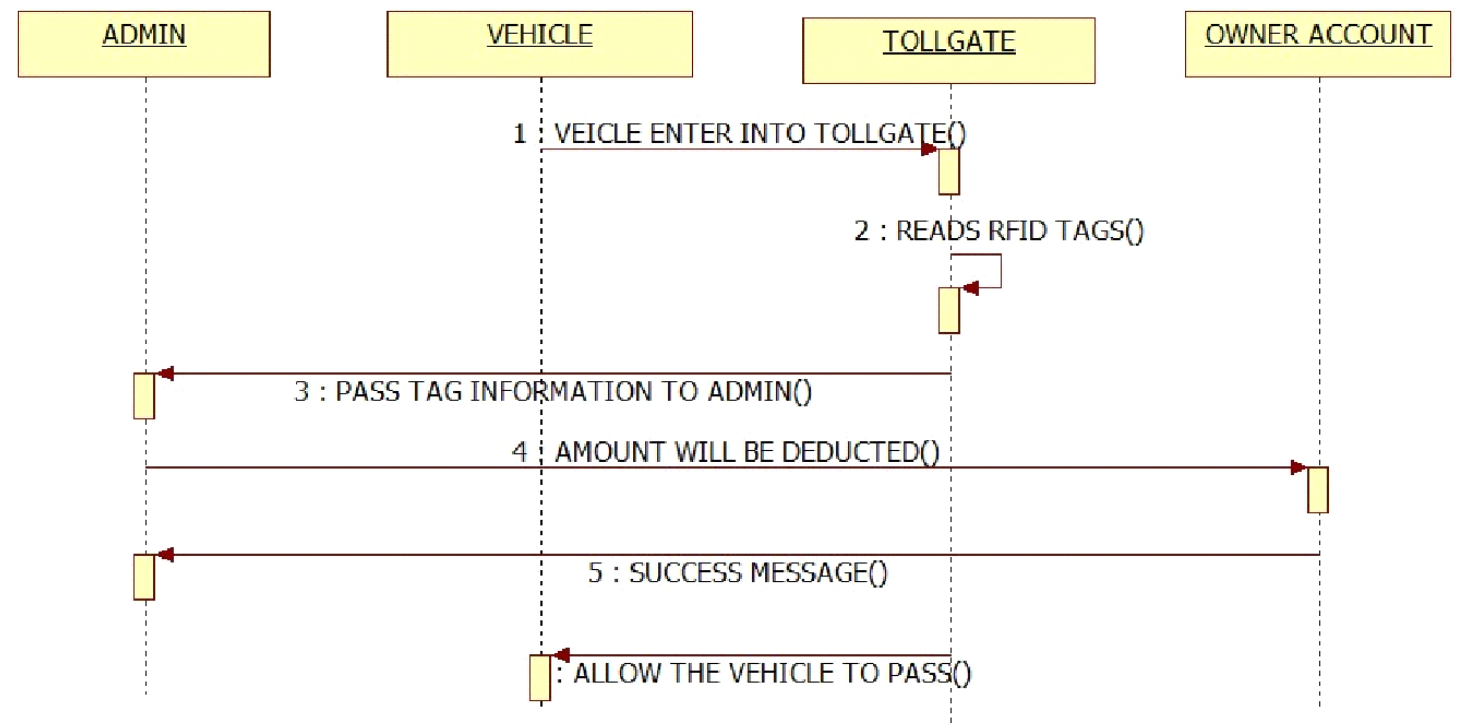

Fig. Sequence Diagram of Process of Vehicle Passing a Tollbooth 


\subsection{Activity Diagram}

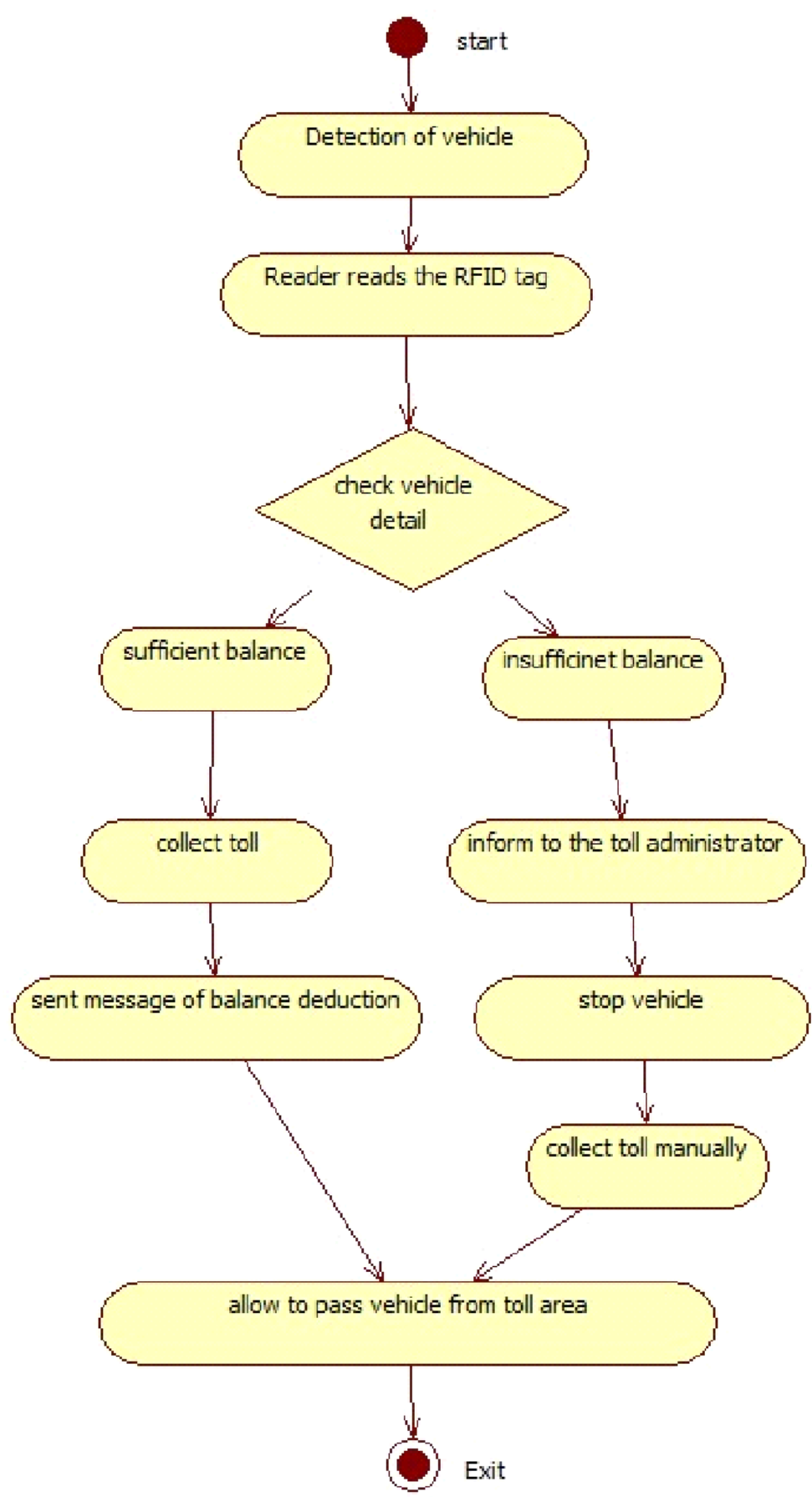

Fig. Activity Diagram

\section{FEATURES}

This RFID Technology is used in Automatic Toll Collection System for collecting toll tax using Android E-Wallet app.In this we identify Tag with the help of radio frequency. Flexibility is the main feature in ATC technology and with the help of slightest changes old toll gate technology can be converted into a new latest implementation. by using the latest technology (RFID), the implementation of this ATC project is very user friendly and simplified. RFID technology combine with a very secure database yields into a highly efficient and secure system. Following are the features and advancement of ATC system:

1. RFID tag can not be get cloned, thats why cheating is not possible.

2. Very efficient saving of time.

3. Wastage of money reduced.

4. Consumption of oil is reduced.

5. Pollution is reduced to a large extent. 
6. Speedy transport.

7. Less congestion on the roadways.

8. Comparatively less maintenance cost

\section{OBJECTIVES}

1. COLLECTION OF TOLL TAX:

The biggest objective of the system is to collect the toll tax automatically and give the correct money to the admin by e-wallet system.

2. EASY TO FIND OUT THEFT VEHICLES-

Whenever user register the complaint about theft vehicle at that time this complaint also register on toll booth database, when stolen vehicle comes to the toll booth both barrier get closed and we can find the stolen vehicle.

3. AUTOMATIVE SYSTEM:

In that system user can register himself/herself using android application and makes entry into the database.it makes transaction very easy for automatic deduction of balance.

4. TIME SAVING

Whenever user register the complaint about theft vehicle at that time this complaint also register on toll booth database, when stolen vehicle comes to the toll booth both barrier get closed and we can find the stolen vehicle.

\section{ADVANTAGES}

1. Reduces the man power.

2. Minimizes work stress

3. Makes traveling more convenient, reduces travel times especially during festive seasons when traffic tends to be heavier than normal.

4. Saves fuel and thus increases fuel economy

5. Reduces wait time at toll booths

6. Increase highway capacity. Processes $250-300 \%$ more vehicles per lane, reducing delays and traffic congestion

7. Easy mounting, easy to operate [user friendly]

\section{CONCLUSION}

Android wallet is not replacement of Bank account but it is a technology offering various features. Android offers highly reliable data collection in harsh environments. Android technology can provide new capabilities as well as an efficient method to collect, manage, disseminate, store, and analyze information It not only eliminates manual data entry but also inspires new automation solutions. It fundamentally changes how processes are managed and how businesses operate. Android's attributes provide greater automated tracking capability than existing technologies, and thus create the opportunity to reduce abhor, improve inventory management and generate better market intelligence, leading to lower operational costs and increased revenue generation.

\section{FUTURE SCOPE}

In future we are planning of making this system more accurate and user friendly. Also we will be probably implementing the facility of pre charging the users account. Also we will be looking to send user a transaction of full month which was held on previous month. Apart from these all the major modification that we are planning is to directly link the users credit card if he has not enough sufficient balance to make payment. Using feedback form users can give feedback their complaint and future modifications.

\section{ACKNOWLEDGMENTS}

We take this opportunity to thank our project guide Prof.Amruta Gadekar and Head of the Department Prof.Mangesh Manke for their valuable guidance and for providing all the necessary facilities, which were indispensable in the completion of this project. We also thankful to the Staff members of the Department of Computer Engineering of Dr. D.Y. Patil Institute of Engineering and Technology (DYPIET, Ambi), Talegaon Dabhade, Pune for their valuable time, support, comment, suggestions.

\section{REFERENCES}

[1] Priyanka Chhoriya, "Image Processing Based Automatic Toll Booth in Indian Conditions"http://www.ijetae.com/files/Volume3Issue 4/IJETA E_0413_71.pdf

[2] Shilpa Mahajan, "Microcontroller Based Automatic Toll Collection

System" http://www.ripublication.com/irph/ijict_spl/09_ijict v3n8spl.pdf Aung Myint Win, "RFID Based Automated Toll Plaza System" http://www.ijsrp.org/researchpaper0614/ijsrp-p3009.pdf

[3] Aung Myint Win, "RFID Based Automated Toll Plaza System" http://www.ijsrp.org/research-paper0614/ijsrpp3009.pdf

[4] The Basics of RFID, Veri-Logic, LLC, 2003

[5] Ankita Bhore,Priya Thombre, Punam Pure,Bawana Nimbhorkar,Prof. Gunjan Agre, "Automated toll system for number plate detection andcollection" Vol. 5, Issue 9,IJARCCE,October 2016,ISSN 2278-1021.

[6] Kannan Subramanam. "Number plate detection with application to electronic toll collection system." Vol. 1,Issue 1 .IJIRCCE, March 2013,pp.144-148.

[7] S.R.Jog,S.D.Chvan and Rama Takbhate. "Automated toll booth and tracking system for theft vehicle." Vol. 1,Issue 2,IJEECS, 2013,pp.79-83.

[8] S.Kranthi, K.Pranathi, A.Srisaila, "Automatic Number Plate Recognition", available at http://ijict.org/, Vol 2, No 3 (July 2011).
[9] 